\title{
Sources of uncertainty for Monte Carlo modelling with Bayesian analysis for Sub-Saharan off-grid solar PV systems
}

\author{
Hannah Buckland, Aran Eales, Damien Frame, Scott Strachan \\ The University of Strathclyde \\ Hannah.buckland@strath.ac.uk
}

\begin{abstract}
This paper outlines a statistical modelling methodology for predicting sustainability of PV systems installed in Sub-Saharan Africa, with a sustainability analysis of an example PV system in Malawi, 3.5 years after installation. Social and economic risks to project sustainability are identified (through expert survey and community consultation) and the methodology for including these qualitative risks is described. The project sustainability results are given in terms of probable system operational time (as a fraction). For scenario modelling, the P10 result (P10 can be considered as a measure for the best case; only $10 \%$ of cases are better than this) 3.5 years after installation shows how social and economic impacts are predicted to reduce the fraction of time the system is operational to over $1 / 4$ of the expected P10. The caveat to this conclusion, is that social and economic risks (such as component theft/tampering, lack of management, possibility of the grid extending to the area, community leadership and structure) are usually mitigated against at the project planning stage. However, the level and type of mitigation is sporadic and inconsistent and should be given significantly more consideration at project conception.
\end{abstract}

\section{INTRODUCTION}

Limited access to electricity is a significant barrier to social and economic development in Africa and other continents of the world. Conversely, electricity access is a key enabler for development widely recognised as an underlying infrastructure for all sectors of life and highlighted in the United Nation's Sustainable Development Goal 7 as a global high impact development priority [1] [2].

Malawi, in Sub-Saharan Africa, ranks near the bottom of the Human Development Index [3] and the need for electricity access is more acute due to national poverty. $91 \%$ of the population do not have access to electricity, equating to 16 million people [4]. Basic electricity access, such as lighting, is often lacking from rural infrastructure and services, which in turn makes it difficult for extension workers to offer adequate services, such as rural education and health care.

In rural Malawi, solar photovoltaic technology (PV) has been used over the last 10 years and is recognised as a viable solution for improved electricity access. PV systems are particularly suited to a rural Malawian context, due to compounding economic and geographical factors such as limited rural coverage from the Malawian centralized grid, a mainly rural population, and low capital expenditure for PV system investment (when directly compared to other renewable electricity solutions).

Sustainability of off-grid programs in Malawi (as well as a wider developing country context) has remained an ongoing issue for practitioners; ultimately reducing the potential impact of off-grid projects in general.

It is difficult to predict, or ensure through actions, the sustainability of an off-grid solar PV installation due to the complex interplay between technical, economic, social and environmental factors. This difficulty is evident in high proportions of systems that experience early and permanent failure [1].

When measuring sustainability of off-grid solar PV installations particularly in rural Africa, there are many technical and social factors that significantly impact this. As $\mathrm{PV}$ is a renewable energy source, there is also natural resource variability to consider.

Most importantly, although it is widely accepted that social factors will also impact on system sustainability, there is little quantitative data available to determine the level of impact, perhaps due to the difficulty in proving causality and lack of remote system performance monitoring devices.

Various academic and commercial models exist to estimate technical and economic performance of a renewable energy system [5] [6], however there are no models that consider social context. For future PV systems in a low development context to achieve the intended impact and learn from past failure, the design of projects requires a more robust, standardised, quantitative approach to measure and understand the social impact on sustainability.

This study builds upon previous research by the authors [7], which presents sustainability data from 65 installed off-grid PV systems in Malawi and combines the data in a novel way, using Monte Carlo with Bayesian analysis for the first time to compare the sustainability of different projects. In [7] projects are scored within 4 impact categories: technical, economic, social, and organisational. An aggregated (total) sustainability 'score' is then proposed as a good early measure of project sustainability.

Results from a Monte Carlo model with Bayesian analysis are presented to monitor PV system sustainability in Malawi. This case-study provides preliminary sustainability results by estimating the fraction of time the system is operational, compared to the theoretical availability. 


\section{MONTE CARLO MODELLING WITH BAYESIAN ANALYSIS}

Monte Carlo modelling is a useful mathematical technique for analysing uncertain scenarios through probabilistic determinations and is often applied when a problem is difficult to solve analytically [8]. The technique provides whole system statistical outcomes when the probability density functions of various uncertainties in the system are well-known. For example, the effect of technical component uncertainty in a PV installation on the amount of energy produced by the system [8].

Monte Carlo modelling (with complimentary Bayesian analysis) is becoming more prevalent in literature in recent years [9] [10] [11] [12] [13] [14]. Monte Carlo modelling with Bayesian analysis can be applied to estimate outcome metrics of a complex energy system installation (such as financial return or lifetime predictions) which can be useful as project impact indicators.

Through the addition of Bayesian analysis, quantitative and qualitative knowledge can be combined with an element of random determination. As an example, Bayesian analysis is used for a probabilistic, technical-economic analysis of domestic solar PV [9] [15], where expert knowledge of the likelihood of market change is included.

In [9] urban data sets of domestic PV systems and national electricity use data are combined to calibrate a probability distribution model of total electricity use. The methodology outlined in [15] is similar to the methodology developed here, however applies this methodology to financial aspects of PV solar systems, whereas the focus here is system sustainability in a low development context.

Sources of uncertainty for off-grid solar PV systems are multi-faceted and cross-cutting; including technical uncertainty, environmental (resource) uncertainty and social uncertainties. Technical and resource uncertainty are well understood and can be determined through Monte Carlo analysis. Social uncertainties require Bayesian analysis to combine qualitative expert opinion with the sporadic data available.

Social uncertainties include interaction between energy systems and the local population, and can therefore be particularly significant for the sustainability of off-grid solar PV installations in developing countries. The specific community-system interactions and baseline social context for each installation are unique and can significantly affect the sustainability of an off-grid solar PV installation in a developing community.

\section{METHODOLOGY}

The focus of the work presented here is to apply Monte Carlo multi-scenario modelling to represent uncertainty in off-grid PV systems and use Bayesian analysis to represent social uncertainty. Through multi-scenario modelling, the Monte Carlo method samples different sources of project uncertainty (represented as probability density functions). The multiple scenarios are combined to determine project outcome probability in terms of project sustainability. A mathematical model is developed to represent relationships and connections between stochastic variables. The variables are organised in modules, including social aspects through a Bayesian analysis module to represent social aspects.

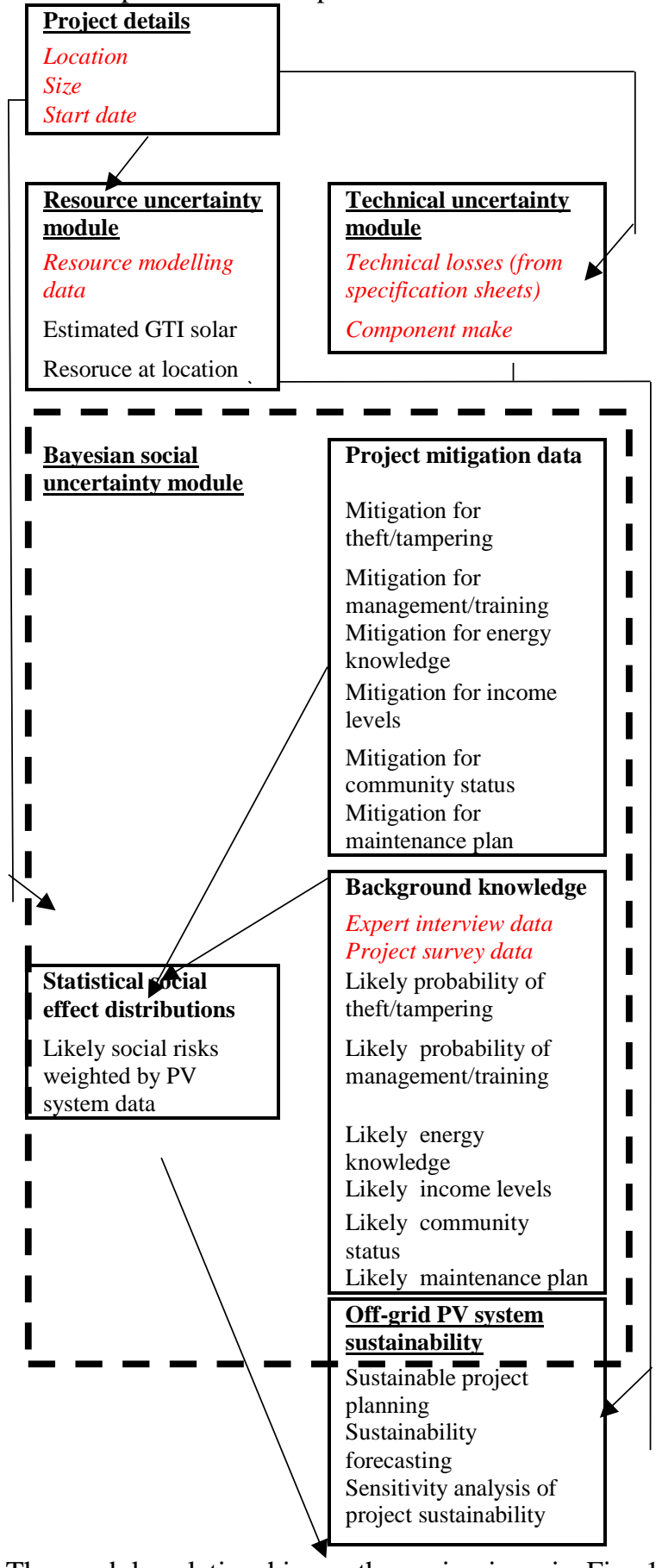

The module relationships pathway is given in Fig. 1 and represents input variables (red) within three uncertainty modules (resource/technical/social).

Fig. 1. A pathway module map for off-grid PV sustainability Monte Carlo calculations performed in the modelling. The input data sets are highlighted in red. 
Using this network between calculation modules as a framework, multi-scenario modelling is applied. The pathway calculations are solved a large number of times where each deterministic variable is discrete. Probability distributions are defined for each variable and sampling occurs over the probability density functions for $\mathrm{N}$ scenarios. In an innovative and novel way, this model combines the quantitative technical and economic aspects effecting solar PV installation with the qualitative social variables effecting a solar PV installation.

For the results presented here the number of scenarios modelled, $\mathrm{N}$, is set to 10,000 . This value is decided through sensitivity analysis of the results to N. Fig. 2 shows the sensitivity of the final results (as presented in Fig. 6 and Fig. 7). From $\mathrm{N}=8,000$ to $\mathrm{N}=10,000$ the most difference is seen in the value for $\mathrm{P} 90$ of fig. 6 , with a difference in value of $<2 \%$.

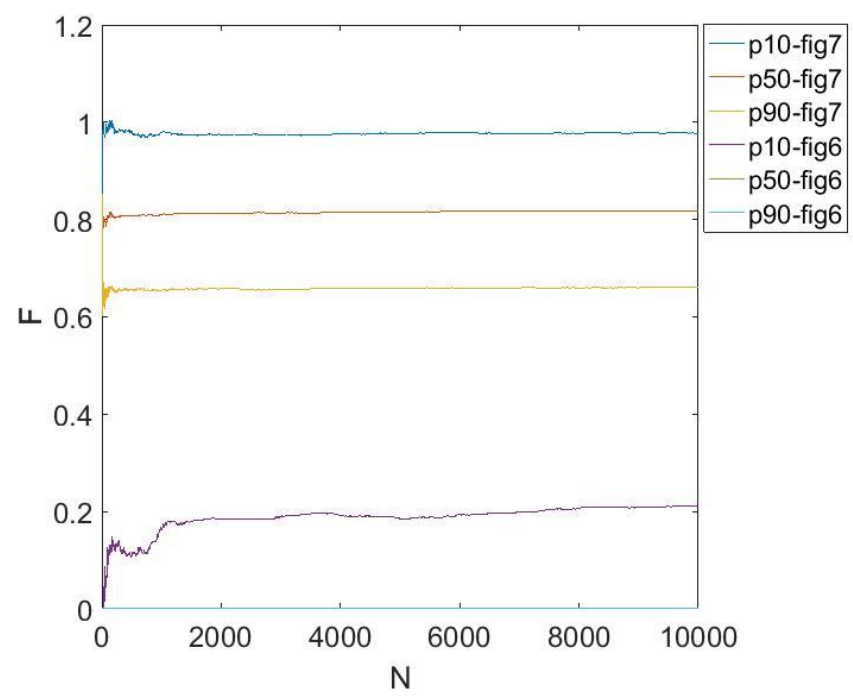

Fig. 2. Sensitivity analysis on the P10, P50, P90 system operational values with full social mitigation, usual social mitigation in Malawi and no social mitigation.

The system monthly performance $p_{m}$ is assumed in this work as a good indicator for sustainability of the system. $p_{m}$ is calculated as:

$$
p_{m}=A * E * H_{m} * U
$$

Where $\mathrm{A}$ is the area of solar panel (i.e. the length, width and number of solar panels multiplied). $E$ is the solar panel yield or efficiency, given by the ratio of electrical power (in $\mathrm{kWp}$ ) of one solar panel divided by the area of one panel. $H_{m}$ is the amount of energy incident on the solar panel per month with units: $\mathrm{KWh} / \mathrm{m}^{2}$ per month. $U$ represents any source of uncertainty and is where technical, resource and social uncertainty is input.

\section{SOURCES OF UNCERTAINTY}

$U$ reduces the system monthly performance, based on many uncertainty factors that can be split into three categories of uncertainty:

- $\quad$ Resource data uncertainty, $U_{R}$; As PV systems are relying on a natural renewable energy source, there is natural variation in solar energy between different years. This natural variation cannot be avoided, but does introduce an inherent amount of uncertainty.

- $\quad$ Technical system uncertainty, $U_{T}$; Including system losses and part failures and replacements.

- Social sources of uncertainty, $U_{S}$; A significant amount of uncertainty arises from social aspects, particularly in a low development country context.

Due to the lack of quantitative understanding of the effect of social factors on off-grid PV systems in rural areas of subSaharan Africa, a Bayesian analysis methodology is presented here as a way to capture and utilise the current wealth of expert knowledge as qualitative data. This can be combined with the social impact data collected in previous research [1] through Bayesian analysis. Using this method to include social aspects of off-grid PV system sustainability within the Monte Carlo model, qualitative based uncertainty is combined with quantitative based uncertainty to produce the most accurate off-grid PV system uncertainty model available.

\section{A. Resource Data Uncertainty}

The resource inputs for this study are taken from a solar resource mapping in Malawi report by The World Bank, Energy Sector Management Assistance Program [16] which reviews and compares all available satellite solar data. The model presented here interpolates between two sets of data from [16]. Climate modelling data Global Horizontal Irradiance (GHI) in terms of average daily and yearly values are given in [16] as an analysis of 20 years of satellite data, shown in Fig. 4. Monthly data is given in [16] in terms of GTI (Global Tilted (in-plane) Irradiation) for specific locations in Malawi. The combination of this data (as given here) is the most accurate estimation of solar resource without obtaining measurement data at a project installation location most accurate estimation of solar resource without obtaining measurement data at a project installation location.

Monthly average daily GTI is given in [16] for 7 specific locations across Malawi (triangle markers in Fig. 4)._Using the Latitude and Longitude of a specific project location in Malawi (red marker in Fig. 4), the model presented here interpolates the nearest GTI (irradiation data). To account for the distance between the GTI data location and the project installation location, the GHI spatial variation in daily resource is utilised to estimate the GTI data at the exact installation location, with the result for resource uncertainty over one year at a location given in Fig. 3. This is a valid methodology as the spatial trend of GTI received by PV modules tilted at optimum angle is similar to GHI [16]. The GTI (irradiation) data gives the average, min and max to account for natural climate variations in different years. As an improvement, GTI data for the location of the installation can be substituted in future (as the data becomes available from satellite modelling and/or site measurement data is taken). 


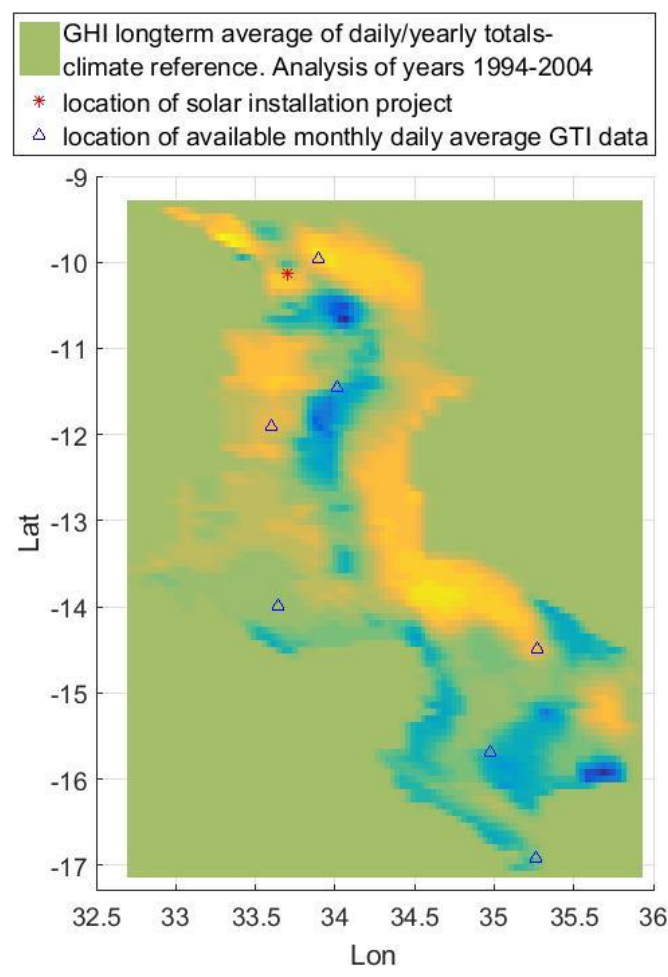

Fig. 4. Yearly average Global Horizontal Irradiance $\left(\mathrm{W} / \mathrm{m}^{\wedge} 2\right)$ spatial plot for Malawi. Analysis of years 1994-2004. Triangle markers are the locations of monthly average GTI (irradiation) data. The red marker is the case study solar project location used in this paper.

In Fig. 3, GTI monthly averages of daily resource (as well as minimum and maximum) are plotted for the example resource uncertainty as used in this paper.

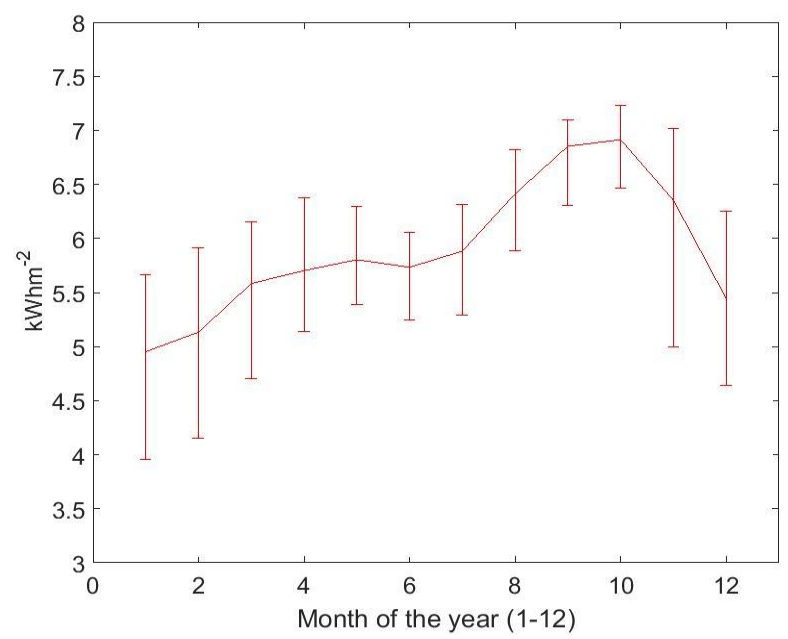

Fig. 3. A location specific Monthly Average Global Tilted (in-plane) Irradiation $\left(\mathrm{kWh} / \mathrm{m}^{\wedge} 2\right)$ over one year with maximum and minimum values plotted.
In addition to providing resource (and as a way of explaining the importance of reducing resource uncertainty) [16] also compares resource uncertainty against PV system project technical uncertainty. Aside from natural climate variations between different years, the satellite data uncertainty (i.e. resource uncertainty) is $7 \%$, where the total uncertainty of the solar installation model is $8.2 \%$ (not considering social uncertainty and impact).

\section{B. Technical System Uncertainty}

Compared to resource uncertainty and social economic uncertainty, technical uncertainty is relatively well understood and easily quantified and estimated. Technical sustainability is defined here as technical temporal losses, component manufacture uncertainties and the maintenance frequency requirements.

These are determined by each component make. In a similar way to Fig. 1, the calculation pathway (specifically for technical uncertainty) is given in Fig. 5.

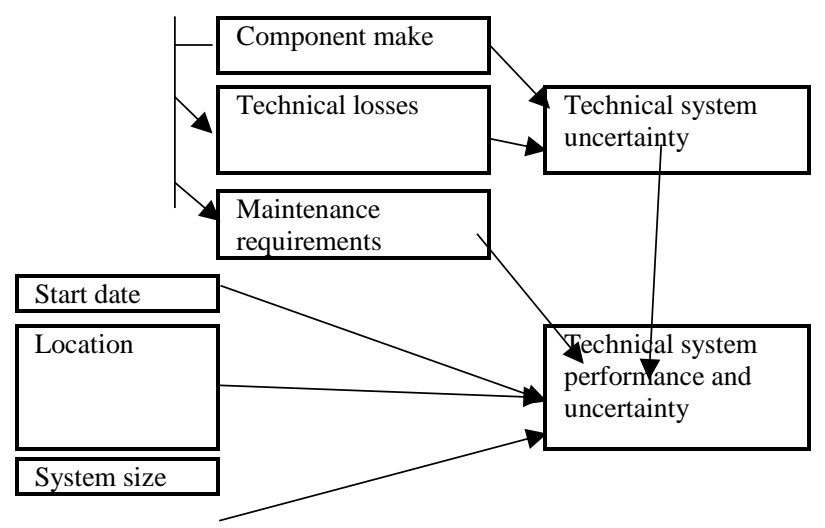

Fig. 5. The calculation pathway for determining technical system performance and uncertainty.

Technical losses are dependent on year since installation (to allow the user to force technical degradation with time) and are assigned a normal (skewed) distribution based on user defined P10, P50 and P90 values for each year, as defined in Table I.

\section{TABLE I}

Definition of P10, P50 and P90 values as used in this analysis

\begin{tabular}{|l|l|}
\hline Distribution variable & Definition \\
\hline P10 & $\begin{array}{l}\text { P10 can be considered as a measure for the best } \\
\text { case; only 10\% of cases are better than this }\end{array}$ \\
\hline P50 & $\begin{array}{l}\text { P50 is the median; 50\% of cases are less/50\% } \\
\text { of cases are more }\end{array}$ \\
\hline P90 & $\begin{array}{l}\text { P90 can be considered as a measure for the } \\
\text { worst case; } 90 \% \text { of cases are better than this }\end{array}$ \\
\hline
\end{tabular}

The unavoidable technical losses considered in the model are given in Table II as well as a description. 
TABLE II

Technical model variable names, descriptions and year 1 values, noting that these values can be changes depending on the year to simulate technical temporal degradation

\begin{tabular}{|l|l|}
\hline $\begin{array}{l}\text { Technical model } \\
\text { variable (losses) }\end{array}$ & Technical model variable description \\
\hline$l_{i n v}$ & inverter losses (6\% to $15 \%)$ \\
\hline$l_{t p}$ & temperature losses (6\% to $15 \%)$ \\
\hline$l_{D C}$ & DC cables losses (1 to $3 \%)$ \\
\hline$l_{A C}$ & AC cables losses (1 to $3 \%)$ \\
\hline$l_{i r}$ & Weak irradiation $3 \%$ to $7 \%$ \\
\hline$l_{S h}$ & Shading from structures/trees $3 \%$ to $7 \%$ \\
\hline$l_{d u}$ & Dust (2\%) \\
\hline
\end{tabular}

The total technical uncertainty $U_{T}$ is comparatively easily determined by combining the individual uncertainties and is dependent on the year $(y)$. A further two solar panel spatial factors are included in calculating $U_{T}$ :

1. $l_{\text {azimuth }}$ is the actual angle of the solar panel compared to true north (in the case of Malawi)

2. $l_{\text {tilt }}$ is the actual angle of the solar panel with the ground and will significantly affect performance

$$
\begin{aligned}
U_{T}(y)= & \left(1-l_{\text {inv }}\right) *\left(1-l_{t p}\right) *\left(1-l_{D C}\right) *\left(1-l_{A C}\right) \\
& *\left(1-l_{\text {ir }}\right) *\left(1-l_{S h}\right) * \\
& \left(1-l_{d u}\right) *\left(1-l_{\text {azimuith }}\right) *\left(1-l_{\text {tilt }}\right)
\end{aligned}
$$

In addition to component performance uncertainty (described here as $U_{T}(y)$ ), there is a degree of uncertainty around when a component will reach its technical lifetime and need to be replaced, this is also input into the model, based on component make and with a normal distribution around the expected lifetime.

\section{B. Social Economic Sources of Uncertainty}

Compared to technical and resource uncertainty, socio economic sources of uncertainty are qualitative. In this study, two distributions combine to give a social and economic uncertainty distribution:

1. Likelihood distribution; the likelihood of the 'risk' event occurring in the first place.

2. Effect distribution; the effect of the 'risk' event on the system performance (in terms of length of time to fix) once it occurs.

In 2017, ten solar installation practitioners and ten communities in Malawi were asked to identify, from their experiences, any social action (or lack of action) that they believe contributes to solar energy system failure. 34 social and economic risks were identified, spanning component theft/tampering, lack of management, possibility of the grid extending to the area, community leadership and structure.

The interviewees were asked to assess the likelihood of the event occurring on a scale of 1 to 5 . The scores were combined to form a likelihood distribution. No specific location was given and the practitioners and communities were asked to identify 'risk' events to sustainability that can occur anywhere in Malawi, therefore the list of 'risk' events is applicable nationally. The effect distribution for each social risk is determined by which category the risk is in. There are 4 categories, as shown in Table III.

\section{TABLE III}

Category definitions for social/economic effect on sustainability

For each of the 10,000 Monte Carlo scenarios, the likelihood distribution is used to determine if the social risk has occurred or not. If the social risk occurs, the effect distribution is determined by the issue severity.

\begin{tabular}{|l|l|}
\hline Catagory & Effect on sustainability \\
\hline $\begin{array}{l}\text { Mean } \\
\text { Time To } \\
\text { Repair }\end{array}$ & $\begin{array}{l}\text { P10/P50/P90 time taken (in months) for a replacement part } \\
\text { to be paid for and arrive and be installed (i.e. time between } \\
\text { system failure due to complete part failure to a } \\
\text { replacement part installed and working) }\end{array}$ \\
\hline $\begin{array}{l}\text { Technician } \\
\text { needed to } \\
\text { fix }\end{array}$ & $\begin{array}{l}\text { P10/P50/P90 time taken (in months) for a capable } \\
\text { technician to attend when the system is down (i.e. time } \\
\text { between system failure to the system running again after } \\
\text { the technician has fixed the issue) }\end{array}$ \\
\hline $\begin{array}{l}\text { Local } \\
\text { community } \\
\text { can fix }\end{array}$ & $\begin{array}{l}\text { P10/P50/P90 time taken (in months) for a local fix to be } \\
\text { applied by the local community. (i.e. time take between } \\
\text { failure due to a small issue to the system being up and } \\
\text { running again after the local community has fixed the } \\
\text { minor issue) }\end{array}$ \\
\hline $\begin{array}{l}\text { Underlying } \\
\text { backgroun } \\
\text { d issue }\end{array}$ & $\begin{array}{l}\text { The effect is ongoing continuous effect, rather than } \\
\text { discrete. The effect is calibrated against the effect of } \\
\text { replacement/technician or local community fix. }\end{array}$ \\
\hline
\end{tabular}

\section{RESULTS}

The model is run for a typical system size in Malawi of 4 solar panels each $85 \mathrm{Wp}$ (340Wp total), representative of a system installed on a school block. The sustainability results are expected to be non-linear with time and future work will be to determine the relationship between sustainability and system size. In the results presented here, the normalisation constant is the $p_{R} P 50$ (median) monthly power when only resource variations are considered $p_{R}$.

$$
p_{R}=A * E * H_{m} * U_{R}
$$

This constant is therefore representative of the theoretical maximum (assuming no technical losses and no social or economic risks considered). $p_{R} P 50$ is a constant at any given time, but will vary with time.

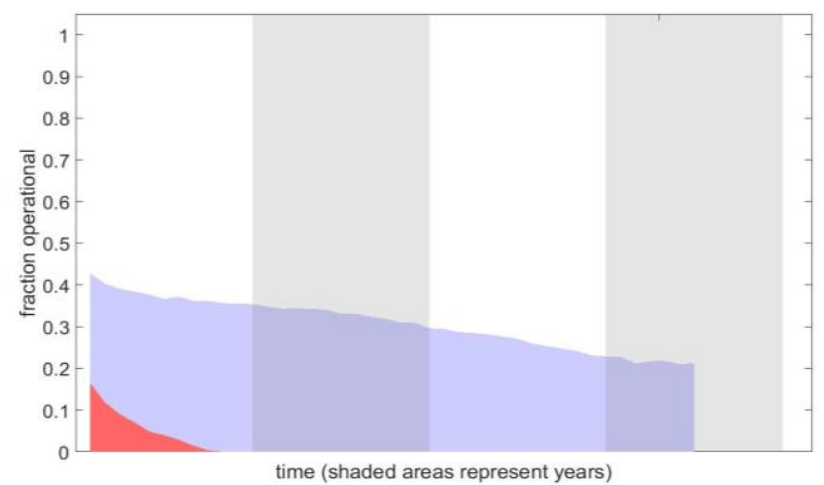

Fig. 6. MonteCarlo model of PV project $\mathrm{F}$ from start date to 3.5 years (shaded areas) with resource uncertainty, technical uncertainty and socio-economic uncertainty. 


$$
\begin{aligned}
& p_{m}=A * E * H_{m} * U_{T} * U_{R} * U_{s} \\
& F=p_{m} /\left(p_{R} * P 50\right)
\end{aligned}
$$

The result $F$ can be considered as a sustainability metric. Fig. 6 shows the results of the model run with all the social and economic risks present, in terms of fraction of time the system is operational. This is shown from installation to 3.5 years. The top of the blue area represents the P10 (best case) result. The mid-line between the two coloured areas represents the P50 result and the bottom edge of the red shaded area represents the p90 result (worst case). It is obvious that this result is highly dependent on the specific social and economic risks included. However, for the sake of brevity, the full breakdown of the social and economic risks is not presented here; but rather the example illustrates how important the combined effect of these risks can be for a PV system in rural Sub-Saharan Africa. Similarly, Fig. 7 shows the results of the model run without any social or economic risks considered, but retaining the resource uncertainty and technical losses. Comparing Fig. 7 with Fig. 6, it is clear that the social and economic risks are expected to have a significant detrimental effect on PV system sustainability. Table IV summarises the probability values from the model.

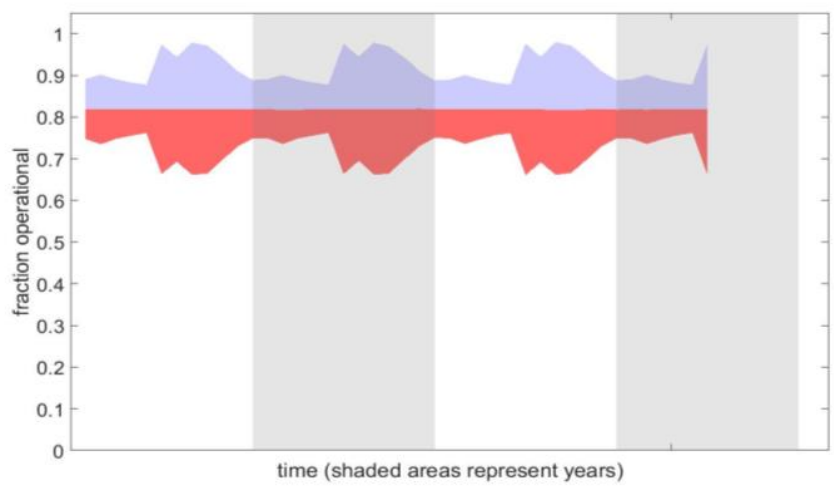

Fig. 7. MonteCarlo model of PV project $\mathrm{F}$ from start date to 3.5 years (shaded areas) with resource uncertainty, technical uncertainty only (no social economic uncertainty).

TABLE IV

\begin{tabular}{|c|c|c|c|}
\hline \multirow{2}{*}{$\begin{array}{l}\text { Is social/economic } \\
\text { uncertainty considered } \\
\text { alongside technical and } \\
\text { resource? }\end{array}$} & \multicolumn{3}{|c|}{$\begin{array}{l}\text { PV system } F \text { (Normalised monthly } \\
\text { power) } 3.5 \text { years after installation }\end{array}$} \\
\hline & P10 & P50 & P90 \\
\hline yes & $\sim 0.21$ & $\sim 0.00$ & $\sim 0.00$ \\
\hline no & $\sim 0.98$ & $\sim 0.82$ & $\sim 0.66$ \\
\hline
\end{tabular}

Results summary from Fig. 6 and Fig. 7

\section{CONCLUSIONS AND FUTURE WORK}

Preliminary results indicate that capturing socio-economic risk factors is critical to PV system planning and that mitigating these risks can have a profound impact on sustainability, possibly producing 4.6 times more monthly energy (3.5 years after installation) and hence impact. Most projects implement some mitigation of social and economic risks at the planning stage (such as component theft/tampering, lack of management, possibility of the grid extending to the area, community leadership and structure). However, the level and type of mitigation is sporadic and inconsistent. The results presented here are preliminary and are based on the data and knowledge available. The model will be continually expanded to capture further operational experience, practitioner expertise, and quantitative data on technical performance. Future sustainability modelling research will focus on model validation against PV system functionality data. This study highlights the real need for system remote monitoring methods. Quantitative system functionality data will greatly improve the accuracy of the model.

\section{ACKNOWLEDGMENT}

This research is supported by the Scottish Government.

\section{REFERENCES}

[1] International Energy Agency, "Africa Energy Outlook; A focus on energy prospects in sub-Saharan Africa," World Energy Outlook special report, 2014.

[2] United Nations. (2016). Sustainable Development Goal 7: Ensure access to affordable, reliable, sustainable and modern energy for all. [Online]. Available: https://www.un.org/sustainabledevelopment/energy/. [Accessed 1201 2017].

[3] United Nations Development Programme, "Human Development Reports," 2017. [Online]. Available: http://hdr.undp.org/en/indicators/137506. [Accessed 1201 2017].

[4] World Bank, IEA, ESMAP, "Sustainable Energy for All (SE4ALL) database from the SE4ALL Global Tracking Framework," 2017. [Online]. Available: https://data.worldbank.org/indicator/EG.ELC.ACCS.ZS?end=2014\&location $\mathrm{s}=\mathrm{MW} \&$ start $=1990 \& \mathrm{view}=$ chart. [Accessed 2017].

[5] H. Buckland, D. Frame, P. Dauenhauer, A. Eales, S. Strachan, "Sustainability of Solar PV systems in Malawi," Sumbitted to the Scottish Government, 2017.

[6] S. Raychaudhuri, "Introduction to monte carlo simulation," Simul. Conf., vol. WSC 2008, p. 91- 100, 2008.

[7] P. A. Leicester, C. I. Goodier, P. Rowley, "Probabilistic evaluation of solar photovoltaic systems using Bayesian networks: a discounted cash flow assessment," Progress in photovoltaics: Research and applications, pp. 1592-1605, 2016.

[8] S. Shah, "De-risking tidal energy project development through improved uncertainty analysis," PhD thesis (draft), The University of Edinburgh, Edinburgh, 2017.

[9] M. Gui, Member 1EEE, Anil Pahwa, Fellow IEEE, and Sanjoy Das, "Bayesian Network Model With Monte Carlo Simulations for Analysis of Animal-Related Outages in Overhead Distribution Systems," IEEE Transactions on Power Systems, vol. 23, no. 3, 2011.

[10] Offshore Renewable Energy Catapult (OREC), "Wave and Tidal Energy Yield Uncertainty Reference Document," 2015.

[11] S. Shah, H. Buckland, P. R. Thies, T. Bruce, "Combining tidal energy yield uncertainties," 2016.

[12] M. E. Glickman and D. A. van Dyk, "Basic Bayesian Methods," in Methods in Molecular Biology, Totowa, NJ, Humana Press Inc, pp. 319-338.

[13] P.A. Leicester, C.I. Goodier and P. Rowley, "Using a bayesian network to evaluate the social, economic and environmental impacts of community deployed renewable energy," Scartezzini, J.L. (ed.) Proceedings of CISBAT, Clean Technology for Smart Cities and Buildings, Lausanne, 2013.

[14] The World Bank, Energy Sector Management Assistance Program, "Solar Resource Mapping in Malawi, Interim output," March 2015. 